Biogeosciences, 10, 4957-4971, 2013

www.biogeosciences.net/10/4957/2013/

doi:10.5194/bg-10-4957-2013

(C) Author(s) 2013. CC Attribution 3.0 License.

\title{
Automated quality control methods for sensor data: a novel observatory approach
}

\author{
J. R. Taylor ${ }^{1,2}$ and H. L. Loescher ${ }^{1,2}$ \\ ${ }^{1}$ National Ecological Observatory Network, Boulder, Colorado, USA \\ ${ }^{2}$ Institute for Arctic and Alpine Research, University of Colorado, Boulder, Colorado, USA \\ Correspondence to: J. R. Taylor (jtaylor@neoninc.org)
}

Received: 5 November 2012 - Published in Biogeosciences Discuss.: 14 December 2012

Revised: 14 June 2013 - Accepted: 16 June 2013 - Published: 24 July 2013

\begin{abstract}
National and international networks and observatories of terrestrial-based sensors are emerging rapidly. As such, there is demand for a standardized approach to data quality control, as well as interoperability of data among sensor networks. The National Ecological Observatory Network (NEON) has begun constructing their first terrestrial observing sites, with 60 locations expected to be distributed across the US by 2017. This will result in over 14000 automated sensors recording more than $>100 \mathrm{~Tb}$ of data per year. These data are then used to create other datasets and subsequent "higher-level" data products. In anticipation of this challenge, an overall data quality assurance plan has been developed and the first suite of data quality control measures defined. This data-driven approach focuses on automated methods for defining a suite of plausibility test parameter thresholds. Specifically, these plausibility tests scrutinize the data range and variance of each measurement type by employing a suite of binary checks. The statistical basis for each of these tests is developed, and the methods for calculating test parameter thresholds are explored here. While these tests have been used elsewhere, we apply them in a novel approach by calculating their relevant test parameter thresholds. Finally, implementing automated quality control is demonstrated with preliminary data from a NEON prototype site.
\end{abstract}

\section{Introduction}

Observational ecology has historically focused on plotstand-ecosystem-watershed scales that are meant to be representative of a larger ecosystem or region. By measur- ing many ecological variables in great detail within these scales, conclusions about larger-scale behavior can be drawn (Schneider, 2001; Schimel et al., 2011). With the advent of satellite observations, measurements can be made on a global scale, but the number of ecologically relevant variables is often limited, and the linkage to ground-based measurements can be lacking (DeFries et al., 2002). In an effort to envelop a larger sphere of inference and to increase our ability to scale ecology in time and space, many terrestrial-based research stations have merged to form national and international networks (and observatories) in which many measurements can be made at numerous locations; for example, Long Term Ecological Research (LTER: Franklin et al., 1990); United States Climate Reference Network (USCRN: Karl et al., 1995); Department of Energy - Atmospheric Radiation Measurement network (DOE-ARM: Stokes and Schwartz, 1994); FLUXNET (Baldocchi et al., 2001); Global Lakes Ecological Observation Network (GLEON: Hanson, 2008); Critical Zone Observatory (CZO: Brantley et al., 2006); Integrated Carbon Observatory System (ICOS: http://www. icos-infrastructure.eu); Terrestrial Environmental Observatories (TERENO: Zacharias et al., 2011); and now the National Ecological Observatory Network (NEON: Keller et al., 2008). In order to facilitate these observations, modern technological advances have allowed for vast arrays of automated environmental sensors that can record high-frequency data with minimal manual intervention and at relatively low cost (Porter et al., 2009). The primary challenge associated with these sensor networks is the establishment of consistent data standards and compatibility across the entire network. The final goal is to develop a framework for comparison among these networks and observatories by using 
accepted, statistically defensible approaches when comparing whole measurement systems or individual instruments as part of a larger rigorous quality assurance and data quality control program (Loescher et al., 2005; Ocheltree and Loescher, 2007).

The NEON is currently constructing a continental-scale observatory consisting of 20 eco-domains in the US, including Alaska, Hawaii, and Puerto Rico (Fig. 1). Each of NEON's eco-domains has one representative "core site" that will monitor the location continuously for $30 \mathrm{yr}$ and two "relocatable sites" that will also operate continuously but will move every $5-10 \mathrm{yr}$ in order to address specific research directives of interest for that domain (as decided by the research/user community). All the sites will contain a large suite of automated terrestrial sensors mounted on towers, placed in streams, and distributed in arrays of soil plots. In addition, 10 mobile towers (with supporting infrastructure) will be made available to rapidly deploy to targets of opportunity that otherwise would not be able to capture key ecological information, e.g., immediately after a fire, flood, or insect outbreak. NEON's construction is currently scheduled to end in 2017, at which time there will be more than 14000 automated terrestrial sensors integrated into operations.

NEON is novel by design. It is the first ecological observatory linking site-based organismal ecology with abiotic drivers and with regional spatial scaling. Taken in concert, these observations embrace the cause-and-effect paradigm. It is also novel in that each of these subsystems has been designed with the other subsystems in mind, making it the first truly integrated ecological observatory. By providing measurements/procedures that are traceable to nationally and internationally recognized standards, a consistent, integrated, and interoperable approach can be used to enable a consistent means of data management and data quality. A complete description can be found in the NEON Science Strategy document (Schimel et al., 2011). NEON's approach is at the forefront of many other observatories that are currently incorporating interoperability into their design so as to enable a global "network of networks" (GEO, 2010; NRC, 2011; Suresh, 2012; IOM, 2013; USGCRP, 2013).

As large volumes of raw sensor data $\left(>100 \mathrm{~TB} \mathrm{yr}^{-1}\right)$ are anticipated by these extensive, emergent networked observatories, it is imperative that a comprehensive data quality assurance and quality control philosophy be adopted. In the broadest sense, quality assurance (QA) defines the overarching plan for minimizing error and maximizing quality, while quality control (QC) refers to the actual procedures that are implemented as part of the QA plan (ISO/IEC 17025 2005, Peppler et al., 2008). While there is no universal QA/QC system for optimizing data quality, a number of common approaches have been implemented by large observation-based networks (Table 1). In an effort to devise an efficient and effective quality assurance program for NEON's automated terrestrial measurements, the optimal components of these various quality assurance programs have been adopted (Taylor and Loescher, 2011).

A core premise in the formalism of complex quality control is to scrutinize the validity of data in a multitude of ways and to consider as many different types of error as possible (Gandin, 1969). To achieve this, NEON's QA plan was based on a traditional "three-stage" approach to data quality control (Durre, 2008). The first stage focuses exclusively on automated quality control procedures in which all acquired data are screened by automated algorithms to identify suspect data that are then flagged for further investigation in the next stage. This second stage of QC performs data verification by means of visual inspection; any flagged data from the previous stage is either verified as being of poor quality or is accepted as high-quality data that are evidentiary of an uncommon event. This approach minimizes the risk of inadvertently eliminating the observation of a rare and potentially interesting event for the sake of data quality (Essenwanger, 1969), and is consistent with the main principle of complex QC in that no decision about the data is made until all possible forms of QC tests have been performed (Gandin 1988). The third stage relies on independent auditing of the accepted dataset through an internally consistent (NEON) auditing plan as well as through external input from the user community. The end result is data that are of the highest quality and are maintained at this level through necessary reprocessing of data and version control. It should also be noted that a robust QA/QC plan also includes steady-state sensor calibration to traceable standards, and field validation activity, which are not the subject of this study.

This paper will focus exclusively on the automated QC methods that occur in the first stage, which are commonly referred to as plausibility tests (O'Brien and Keefer, 1985; Foken and Wichura, 1996; Foken et al., 2004; Fiebrich et al., 2010). Other aspects of automated quality control, such as redundancy tests, time series analysis, comprehensive uncertainty estimation, etc., will be addressed in a later paper. Because of NEON's large network size and $30 \mathrm{yr}$ observational lifetime, it is prudent to adopt a "data-driven approach" for the first stage of automated QC. The principal philosophy behind this approach is to optimize human resources (both in the field and in the lab) by maximizing computer automation (Smith et al., 1996). While the implementation of fully automated approaches has been well documented for individual observation sites (Meek and Hatfield, 1994), it has proven to be challenging for large networks (Shafer et al., 2000).

In comparison to the approaches that have been utilized by other networks (Table 1), the methods presented here are philosophically similar but they will be implemented in a much more uniform, comprehensive, and automated way. In addition, they are driven almost exclusively by a datadetermined approach. As much as possible, this minimizes subjective, user-based decisions and attempts to automate quality choices with guidance from existing data. While most of the techniques used by other networks also implement 


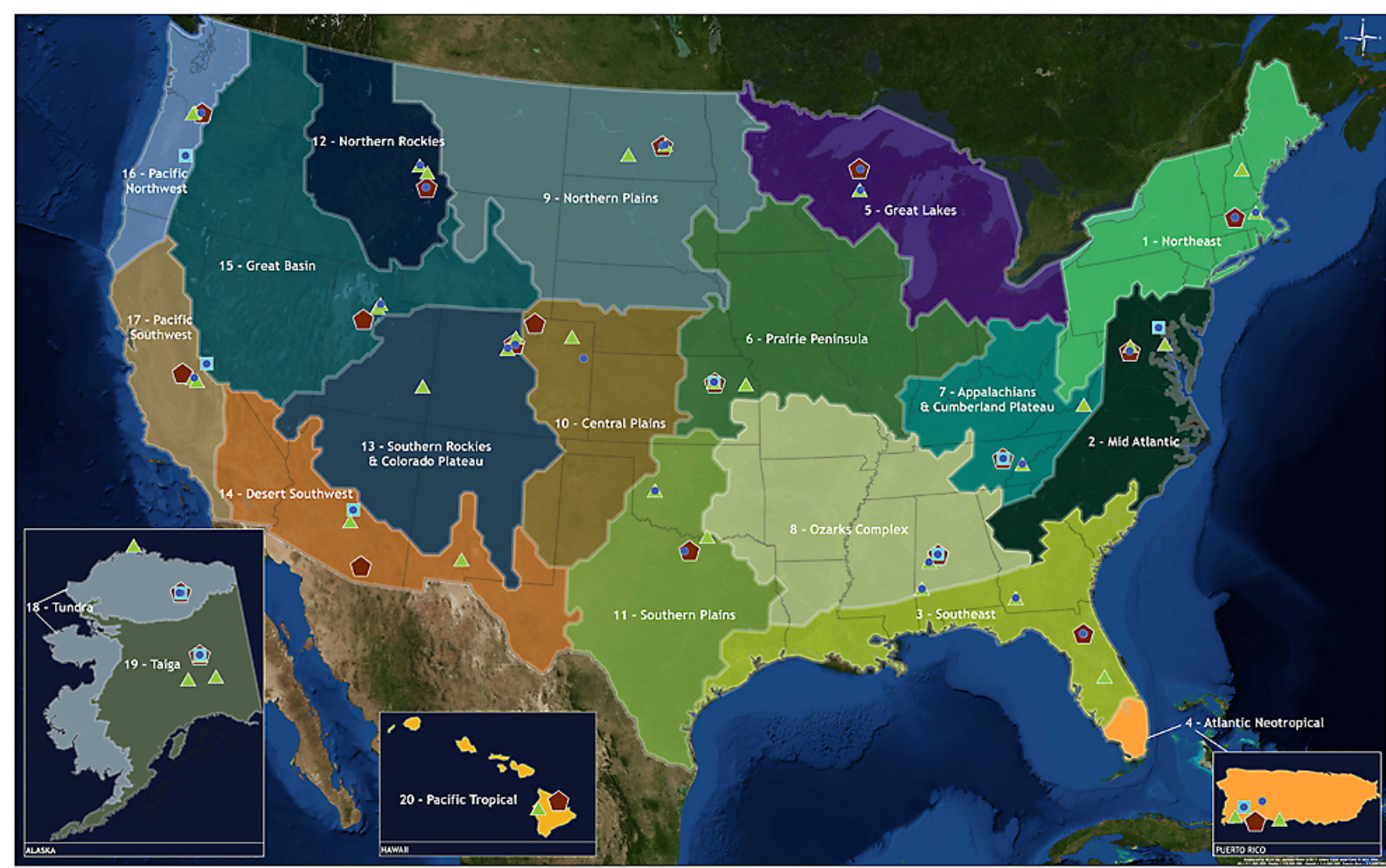

Site Legend $\quad$ NEON Candidate Aquatic $\triangle$ NEON Candidate Relocatable
NEON Candidate STREON $\triangle$ NEON Gandidate Gore

Fig. 1. NEON's 20 eco-domains and their associated ecological research sites. "Core sites" monitor the ecosystem continuously for 30 yr while "relocatable sites" are moved every 5-10 yr in order to address specific research questions in a given domain. Some aquatic sites also include an embedded experiment called STREON (see the NEON Science Strategy document for more details; Schimel et al., 2011).

automated quality control methods, decisions are often based on arbitrary rules and can be implemented in inconsistent, ad hoc ways. The robust, automated QA/QC methods proposed here are further motivated by the need to optimize staff effort for field maintenance, which has direct budgetary implications for long-term observations.

In practice, plausibility tests are essentially binary "pass/fail" checks that are automatically applied to every single observation (Graybeal et al., 2004). The pass/fail parameters for each test are calculated directly from the data and stored in look-up tables. Because these parameters will be unique for each sensor, each measurement type, and each location, they will need to be dynamically updated on a regular basis and, potentially, be maintained at a seasonal or monthly resolution. The theoretical basis for establishing this approach, as well as a novel methodology for implementing it, is the objective of this paper. A simple example applied to a limited number of sensors will also be shown. Finally, the limitations of this QC approach will be discussed.

\section{Theory}

\subsection{Plausibility tests}

Plausibility tests can broadly be defined as metrics that examine the range and variability of a given dataset. Here, we describe these tests and how they are applied to the data. It should be noted that nature of sensor data often depends upon the phenomenon measured and not all of these tests will be applicable to every situation. Where possible, examples are used to demonstrate the efficacy of a given test. We apply this approach to observational data collected from a sensor, and assume (i) its field deployment is designed to best capture the phenomena of interest and minimize other systematic biases (Munger et al., 2012), and (ii) more advanced data products derived from multiple sensor datasets may require additional QA/QC approaches.

A range test checks that every recorded observation falls within reasonable minimum and maximum values for a given location and time of year. For example, if the temperature at sea level in Hawaii was observed to be $-30^{\circ} \mathrm{C}$, the range test would flag this as implausible because this is lower than the expected minimum value (i.e., out of range). 
Table 1. Example quality assurance plans currently in use at large environmental observatories.

\begin{tabular}{|c|c|c|c|c|c|}
\hline \multirow{2}{*}{$\begin{array}{l}\text { Network } \\
\text { and Agency }\end{array}$} & \multirow{2}{*}{$\begin{array}{l}\text { Calibration } \\
\text { Activities }\end{array}$} & \multirow{2}{*}{$\begin{array}{l}\text { Data } \\
\text { Acquisition }\end{array}$} & \multicolumn{3}{|c|}{ Quality Control } \\
\hline & & & Level 1 & Level 2 & Level 3 \\
\hline ARM-DOE & $\begin{array}{l}\text { Centralized perfor- } \\
\text { mance verification } \\
\text { with lab testing }\end{array}$ & $\begin{array}{l}\text { Dynamic SOPs, sensor } \\
\text { replacement with trans- } \\
\text { fer standards }\end{array}$ & $\begin{array}{l}\text { Automated quality } \\
\text { control and unit } \\
\text { conversion }\end{array}$ & $\begin{array}{l}\text { Standardized visual } \\
\text { quality inspection }\end{array}$ & $\begin{array}{l}\text { Instrument mentors, } \\
\text { review panels, and } \\
\text { data reprocessing }\end{array}$ \\
\hline $\begin{array}{l}\text { USCRN - } \\
\text { NOAA }\end{array}$ & $\begin{array}{l}\text { Centralized perfor- } \\
\text { mance verification } \\
\text { with lab testing }\end{array}$ & $\begin{array}{l}\text { Dynamic SOPs and } \\
\text { sensor replacement }\end{array}$ & $\begin{array}{l}\text { Automated quality } \\
\text { control and unit } \\
\text { conversion }\end{array}$ & $\begin{array}{l}\text { Standardized visual } \\
\text { quality inspection }\end{array}$ & $\begin{array}{l}\text { Internal NOAA } \\
\text { departmental review }\end{array}$ \\
\hline $\begin{array}{l}\text { Oklahoma } \\
\text { Mesonet - } \\
\text { OU/OSU }\end{array}$ & $\begin{array}{l}\text { Centralized perfor- } \\
\text { mance verification } \\
\text { with lab testing }\end{array}$ & Dynamic SOPs & $\begin{array}{l}\text { Automated quality } \\
\text { control and unit } \\
\text { conversion }\end{array}$ & $\begin{array}{l}\text { Standardized visual } \\
\text { quality inspection }\end{array}$ & $\begin{array}{l}\text { User community } \\
\text { review }\end{array}$ \\
\hline $\begin{array}{l}\text { Canadian } \\
\text { Carbon } \\
\text { Program - } \\
\text { CFCAS }\end{array}$ & $\begin{array}{l}\text { PI-driven, ad hoc per- } \\
\text { formance verification }\end{array}$ & $\begin{array}{l}\text { Dynamic SOPs with } \\
\text { transfer standards }\end{array}$ & $\begin{array}{l}\text { Automated quality } \\
\text { control and unit } \\
\text { conversion }\end{array}$ & $\begin{array}{l}\text { Standardized visual } \\
\text { quality inspection }\end{array}$ & $\begin{array}{l}\text { Internal Environment } \\
\text { Canada/user } \\
\text { community review }\end{array}$ \\
\hline $\begin{array}{l}\text { AmeriFlux- } \\
\text { DOE }\end{array}$ & $\begin{array}{l}\text { PI-driven, ad hoc per- } \\
\text { formance verification }\end{array}$ & $\begin{array}{l}\text { Ad hoc SOPs with } \\
\text { transfer standards and } \\
\text { a roving system }\end{array}$ & $\begin{array}{l}\text { Unit conversion with } \\
\text { non-standardized } \\
\text { quality flags }\end{array}$ & $\begin{array}{l}\text { Ad hoc quality } \\
\text { control performed } \\
\text { at local site }\end{array}$ & $\begin{array}{l}\text { Internal DOE/user } \\
\text { community review }\end{array}$ \\
\hline $\begin{array}{l}\text { SCAN- } \\
\text { USDA }\end{array}$ & $\begin{array}{l}\text { Centralized perfor- } \\
\text { mance verification with } \\
\text { de facto acceptance }\end{array}$ & Dynamic SOPs & $\begin{array}{l}\text { Automated quality } \\
\text { control and unit } \\
\text { conversion }\end{array}$ & $\begin{array}{l}\text { Standardized visual } \\
\text { quality inspection }\end{array}$ & $\begin{array}{l}\text { User community } \\
\text { review }\end{array}$ \\
\hline $\begin{array}{l}\text { USGS Wa- } \\
\text { ter Quality } \\
\text { Monitoring } \\
\text { Network- } \\
\text { DOI }\end{array}$ & $\begin{array}{l}\text { Centralized perfor- } \\
\text { mance verification } \\
\text { with on-site testing }\end{array}$ & $\begin{array}{l}\text { Standardized SOPs } \\
\text { with minor dynamic } \\
\text { modifications }\end{array}$ & $\begin{array}{l}\text { Daily visual quality } \\
\text { review at site }\end{array}$ & $\begin{array}{l}\text { Standardized visual } \\
\text { quality inspection }\end{array}$ & $\begin{array}{l}\text { Internal USGS } \\
\text { Water Service Center } \\
\text { review }\end{array}$ \\
\hline
\end{tabular}

Note: The Atmospheric Radiation Monitoring Network (ARM) is supported by the United States Department of Energy (DOE), (Stokes and Schwartz, 1994) http://www.arm.gov/; the United States Climate Research Network (USCRN) is supported by the National Oceanic and Atmospheric Administration (NOAA), (Karl et al., 1995) http://www.ncdc.noaa.gov/crn/; Oklahoma Mesonet is supported by the University of Oklahoma (OU) and Oklahoma State University (OSU) (McPherson et al., 2007) http://www.mesonet.org/; the Canadian Carbon Program is supported by the Canadian Foundation for Climate and Atmospheric Science (CFCAS) (Margolis et al., 2006) http://www.fluxnet-canada.ca/; the AmeriFlux Network is supported by the United States Department of Energy (DOE) (Baldocchi et al., 2001)

http://public.ornl.gov/ameriflux/; the Soil Climate Analysis Network (SCAN) is supported by the United States Department of Agriculture (USDA) (Schaefer et al., 2007) http://www.ars.usda.gov/main/main.htm; and the United States Geological Survey (USGS) water quality monitoring network is supported by the United States Department of the Interior (DOI) (Wagner et al., 2006) http://water.usgs.gov/owq/.

Two separate and distinct tests are used to check for a realistic fluctuation of values over a designated period of time: the "sigma test" and the "delta test". The sigma test uses the standard deviation or variance of the data over a given period of time and compares it to a given threshold value (threshold definition is discussed below). If the standard deviation is below this sigma threshold then the observations have not varied realistically and the test is failed. The delta test examines the difference between pairs of subsequent observations over a given time period. If the difference is less than the specified delta threshold, then the observations have not varied realistically and the test is failed. By using both of these tests in tandem, an instrument may appear to be functioning correctly but its output that is "stuck" at a constant or near-constant value can be identified. For example, a radiation sensor that is completely covered with snow may report that there is adequate fluctuation between subsequent measurements (i.e., pass the delta test), but the variance over a
$24 \mathrm{~h}$ period will be lower than expected because it is not able to view the daily change in solar radiation (i.e., fail the sigma test). Therefore, these tests would flag the data over this $24 \mathrm{~h}$ period as implausible.

Another test that is used to ensure that changes in a time series of data are realistic over a given period of time is the "step test". It is similar to the sigma and delta tests in that it checks the plausibility of data based on temporal variation, but, rather than be concerned with the minimum fluctuations over a given period of time, the step test scrutinizes the maximum fluctuations in the data. The step test compares successive data points to determine if their difference exceeds a maximum threshold. Missing data points are also typically captured by a "null test". This test focuses the number of missing data points over a given period of time. This is distinct from a "gap test", which identifies long periods of temporal discontinuity in a time series. For example, a compromised connection between a sensor and a data logger could 
result in realistic data variation (i.e., pass the step test) but have an increased number of dropped data points (i.e., fail the null test), so these data would be flagged as implausible. Identifying both the duration and the frequency of gaps in a given time series is crucial for later stages of quality control, such as gap-filling and error analyses, and has significance in the interpretation of natural variations, such as diurnal cycles, seasonal cycles, etc.

\subsection{Test thresholds}

The automated application of these binary plausibility tests is rather straightforward. It is, however, the estimation of the parameter "thresholds" of these tests that poses the greatest and most critical challenge. The statistical assumptions dictate that these threshold parameters are ideally defined by having a distribution of values that are objectively considered "reasonable" for every sensor at every site. The range, step, delta, sigma, null, and gap parameter thresholds can all be rigorously determined by constructing statistical distributions based on existing data over a period sufficiently long to capture the full suite of variability. A representative distribution of range values, for example, is more effective than simply using historical minima and maxima as there is no way to ensure that these data themselves are reasonable, are of quality, and are relevant in a changing climate.

Because the sensors monitor physical quantities that span numerous distributions, it is not always possible to assume one fundamental statistical distribution and calculate the desired threshold quantities. However, as the point of interest is not with the distribution of the data but rather with a statistical quantity derived from these data, a sampling distribution of the statistic can be constructed. Since sampling distributions are constructed from independent randomly sampled data, the central limit theorem states that the distribution will approach a Gaussian distribution as the number of samples approaches infinity (Rice, 2007). Therefore, regardless of the nature of the underlying data, a properly constructed sampling distribution of a statistic based on these data will always follow a Gaussian distribution:

$f(x)=\frac{1}{\sqrt{2 \pi \sigma}^{2}} e^{\frac{-(x-\mu)^{2}}{2 \sigma^{2}}}$,

where $x$ is any random variable, $\mu$ is the population mean of the random variable, and $\sigma$ is the population standard deviation of the random variable. For example, a statistic for the minimum temperature at a given location will have a Gaussian distribution constructed from minimum temperature data points (discrete samples) over desired temporal periods (e.g., hourly, diurnal, monthly, seasonal, annual, decadal, etc.). From this sampling distribution, inferences about the population mean minimum temperature and population minimum temperature standard deviation can be used to define the minimum temperature value that will be used as the threshold parameter for plausibility testing.
Because the Gaussian distribution is unimodal and symmetric, the random variable can be normalized by the standard deviation to yield a curve with the mean value centered at zero (see Fig. 2). When this analysis is completed, the integral between $\mu-3 \sigma$ and $\mu+3 \sigma$ represents $99.7 \%$ of all the data, and the integral over $\mu-2 \sigma$ and $\mu+2 \sigma$ represents $95 \%$ of all the data. By exploiting these properties, we can define consistent and objective threshold parameters for all plausibility tests and, as the data volume increases, these values can easily be reassessed and updated.

Although these parameters can be constructed for all tests, the exact details of the test, such as the sampling period and sample size, will vary depending on the type of observation and sensor. Because these emergent observatories, such as NEON, will be measuring new physical quantities, it may be challenging at times to find enough prior existing data to adequately construct sampling distributions. In these cases, best possible estimates of appropriate test parameters will be constructed for initial plausibility tests and, after a sufficient amount of NEON data have been collected, new parameters will be estimated and periodically updated. In this sense, this data-driven approach requires a "spin-up time" for sufficient data to be available for informing threshold parameter calculations. As observatories continue to make long-term observations, these threshold parameters will require regular maintenance as they will be frequently recalculated from augmented data records.

As is inevitable with almost all statistical inference, there is an element of arbitrary choice in the decision level at which the test parameters are defined. Because plausibility tests are typically the first stage of quality control, it is prudent to estimate these parameter thresholds such that these tests should err on the side of heightened sensitivity. This is based on the philosophy that it is better to flag good data and verify that it is acceptable in the second stage of quality control rather than neglect to flag poor quality data and have it be published as plausible.

For the range test, which relies on checking extreme values, it is necessary to construct sampling distributions of the minima and maxima observed for a given sample period (Table 2). For many variables, the diurnal or semi-diurnal timescales are often chosen as ecologically meaningful (e.g., temperature, radiation, humidity). It should also be noted that the application of the range test to some variables may not be statistically defined and/or quantitatively trivial (e.g., minimum wind speed or maximum wind direction) but can still have merit for detecting implausibility (i.e., a wind direction greater than 360 degrees is implausible). From the constructed distributions of extreme values, acceptable range thresholds are defined by the threshold $\mu \pm 2 \sigma$. By using the twice the standard deviation, $97.5 \%$ of all values are considered acceptable, while the remaining $2.5 \%$ will be flagged as questionable/outliers. At NEON, this threshold calculation will be applied to all incoming data streams unless explicitly stated otherwise. 


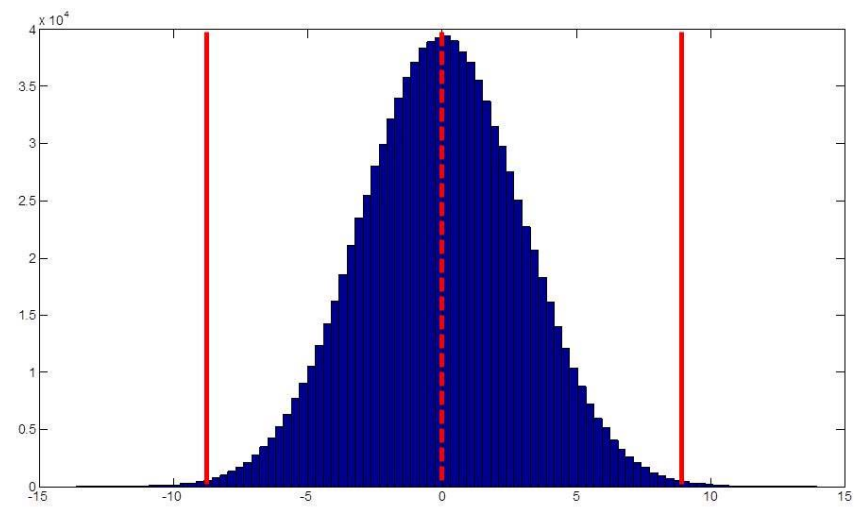

Fig. 2. Histogram of simulated data following a Gaussian distribution with normalized mean 0 (dotted red line) and standard deviation of 3 . The range of values that lie between 3 standard deviations of the mean (solid red lines) represent $99.7 \%$ of all the data.

The sigma test relies on the variance/standard deviation of the sample in a predetermined sampling time (Table 2). It, in essence, scrutinizes the "standard deviation of the standard deviations". Consequently, a sampling distribution of all the sampled standard deviations of the dataset will provide an inference of the minimum/maximum expected variability of a given parameter. A threshold of $\mu \pm 2 \sigma$ (where $\mu$ represents the mean standard deviation of the distribution and $\sigma$ is the standard deviation of the distribution of standard deviations) ensures that only the lowest/highest $2.5 \%$ variability data is flagged. In many cases, care must be taken when scrutinizing the validity of this value and it will often need to be used in conjunction with other plausibility tests to assure data quality. For example, if there is no precipitation over a three day period (a very realistic case), the sigma test alone would reject these data as having 0 variability. This false failure can be corrected by having two-stage tests where " 0 variability conditions" are checked for consistency against other observations and/or plausibility tests.

Similar to the sigma test the delta test scrutinizes the variability of a dataset, but it focuses more on the observed small-scale random variability (i.e., noise) rather than the total sampled variability of a measured phenomenon over a specified period. The delta test utilizes the difference between subsequent observations to check changes in the characteristic random variability. The mean and standard deviation of this sampling distribution represent how small-scale random variability is correlated between subsequent observations throughout the desired time series. If this quantity changes less than the $\mu-2 \sigma$ threshold, data are flagged as being possibly "frozen" at a given value. Again, care must be taken with this test to ensure that observations that commonly read 0.0 are not being inadvertently flagged when the zero values are real natural phenomena. In some cases, it may be advantageous to define the delta test threshold by the sampling precision of the instrument/data acquisition system, rather than statistical analysis of the time series alone. For example, if the resolution of the instrument is 0.005 , then it may be more appropriate for the delta test to utilize a threshold of $\sim 0.01$ to test if values are frozen and only vary near the instrument's resolution.

The same distribution of subsequent observation differences is used to also define the threshold for the step test (Table 2). Rather than scrutinize the smallest acceptable change between measurements, this step test seeks to ensure that there are no implausible, large increases in the variance structure between/among measurements. The threshold is defined as $\mu+2 \sigma$ to ensure that only data exhibiting the largest $2.5 \%$ of all data discontinuities are flagged. However, for this test to be applied to paired data points in an automated fashion, it is simplest to flag both points, thereby resulting in more flags than the $2.5 \%$ would indicate. A subsequent processing of the flagged data (i.e., in the "data verification" stage of QC) could then help identify which of these flagged values is a distinct spike. However, if there is a sort of step-function change in the mean of the time series, then additional verification will be required. It is for this reason that caution must be taken when applying this test and should be accompanied by subsequent visual analyses of the time series for its validation. For example, wind speed and direction can typically have large step changes that would be flagged by this approach when indeed the data are valid.

The null test and gap test are used to monitor the loss of data that could arise from problems associated with the instrument, the data acquisition system, or both. The null test is intended to look for individual, missing data points within a given sampling period, while the gap test is meant to look for an extended period of missing data. The exact threshold for acceptable data loss will vary with the physical quantity being measured, the instrument, and sampling interval. In some cases, this may simply be defined as an arbitrary number (e.g., 0 or 1 maximum missing data value per day) or by a local calibration cycle. For data that are sampled as a continuous daily time series, the statistical approach that has been used to define all plausibility thresholds should continue to be applied. A sampling distribution of the number of missing data values over a given sampling period should be constructed. In almost all cases, these two tests cannot be applied to a raw time series without defining a sampling period in which a known number of samples is expected. As with other parameters, a threshold of $\mu+2 \sigma$ is chosen for flagging data with the null test. It should be noted that these parameters will only be representative of the sampling period, so any portion of the time series in which there are known gaps or null data points (e.g., during a calibration cycle) should be removed prior to estimating the sampling distribution. For data acquisition systems that do not report times with missing data notation, a gap test must be used to explicitly check for missing data.

These six plausibility tests are summarized in Table 2. 
Table 2. The six plausibility tests employed in the first phase of NEON's data quality control.

\begin{tabular}{llll}
\hline $\begin{array}{l}\text { Problem } \\
\text { to be } \\
\text { Identified }\end{array}$ & $\begin{array}{l}\text { Plausibility } \\
\text { Test }\end{array}$ & $\begin{array}{l}\text { Underlying Statistical } \\
\text { Quantity Sampling } \\
\text { Distribution }\end{array}$ & Calculation \\
\hline Data Outliers & Range Test & Extreme Values & $\begin{array}{l}\text { Max: } \mu+2 \sigma, \\
\text { Min: } \mu-2 \sigma\end{array}$ \\
\hline $\begin{array}{l}\text { Change in Variance } \\
\text { Structure }\end{array}$ & Sigma Test & Standard Deviation & $\mu-2 \sigma, \mu+2 \sigma$ \\
\hline $\begin{array}{l}\text { Data Stuck at a } \\
\text { Singular Value }\end{array}$ & Delta Test & $\begin{array}{l}\text { Differences of } \\
\text { Subsequent Pairs }\end{array}$ & $\begin{array}{l}\mu-2 \sigma \\
\text { (or defined by sampling) }\end{array}$ \\
\hline $\begin{array}{l}\text { Jumps in Data } \\
\text { Values }\end{array}$ & Step Test & $\begin{array}{l}\text { Differences of } \\
\text { Subsequent Pairs }\end{array}$ & $\mu+2 \sigma$ \\
\hline $\begin{array}{l}\text { A Dropped Data } \\
\text { Point }\end{array}$ & Null Test & Missing Data & $\begin{array}{l}\mu-\sigma \\
\text { (or defined by sampling) }\end{array}$ \\
\hline $\begin{array}{l}\text { Multiple Dropped } \\
\text { Data Points }\end{array}$ & Gap Test & $\begin{array}{l}\text { Large Gap of } \\
\text { Missing Data }\end{array}$ & Defined by Sampling \\
\hline
\end{tabular}

While a Gaussian probability distribution function (Eq. 1) can be constructed manually from historical climate data for many variables, this process is computationally expensive and inefficient for the amount of data generated by large observatories. Without loss of generality, an algorithm that calculates the first two moments of a Gaussian distribution (the mean and variance, respectively) can be constructed discretely to be

$\bar{x}(d)=\frac{\sum_{y}^{H(d)} x(d, y)}{\sum_{y}^{H(d)} 1}$
$\sigma^{2}(d)=\frac{\sum_{y}^{H(d)}[x(d, y)-\bar{x}(d)]^{2}}{\sum_{y}^{H(d)} 1}$,

where $x$ is a measurement statistic on a given day, $d$, with a historical dataset of measurements on this day, $H(d)$, and $\bar{x}$ and $\sigma^{2}$ are the derived mean and variance for this measurement statistic. For example, this could be a dataset of daily maximum temperatures observed at a specific location for $30 \mathrm{yr}$.

While this approach is computationally more efficient than manually constructing these parameters, it does not include all available information, such as temporally and spatially adjacent observations. Once an observatory's (or network's) operational phase has begun and there are more data representative of the spatial and temporal variation available, algorithms utilizing a combined approach for defining plausibility parameters will be more appropriate (Hasu and Aaltonen 2011). As the spatio-temporal correlation length scales are unique to each measurement statistic, a useful approach is to incorporate weighting factors for their respective influence. This results in the following modifications to Eqs. (2) and (3):

$$
\begin{gathered}
\overline{x_{i}}(d)=\frac{\sum_{j}^{N_{i}} \sum_{d^{\prime}}^{D_{\mathrm{d}}} \sum_{y}^{H\left(d^{\prime}\right)} w_{1}(j, i) \cdot w_{2}\left(d^{\prime}, d\right) \cdot x_{j}\left(d^{\prime}, y\right)}{\sum_{j}^{N_{i}} \sum_{d^{\prime}}^{D_{\mathrm{d}}} \sum_{y}^{H\left(d^{\prime}\right)} w_{1}(j, i) \cdot w_{2}\left(d^{\prime}, d\right)}, \\
\sigma_{i}^{2}(d)=\frac{\sum_{j}^{N_{i}} \sum_{d^{\prime}}^{D_{\mathrm{d}}} \sum_{y}^{H\left(d^{\prime}\right)} w_{1}(j, i) \cdot w_{2}\left(d^{\prime}, d\right) \cdot\left[x_{j}\left(d^{\prime}, y\right)-\overline{x_{i}}(d)\right]}{\sum_{j}^{N_{i}} \sum_{d^{\prime}}^{D_{\mathrm{d}}} \sum_{y}^{H\left(d^{\prime}\right)} w_{1}(j, i) \cdot w_{2}\left(d^{\prime}, d\right)},
\end{gathered}
$$

where $N_{i}$ is the set of neighboring sites measuring the same quantity, $D_{\mathrm{d}}$ is the set of adjacent dates upon which the quantity is measured, and $w_{1}$ and $w_{2}$ represent the spatial and temporal weighting factors, respectively. These weighting factors are defined as

$$
\begin{aligned}
& w_{1}(j, i)=\left\{\begin{array}{clrl}
0, & & j \notin N_{i} \\
1, & & j=i \\
\frac{1}{2} e^{-\left(\frac{\left|\Delta_{i j}\right|}{z}\right)^{2}}, & & j \in N_{i} /\{i\}
\end{array}\right. \\
& w_{2}\left(d^{\prime}, d\right)=\left\{\begin{array}{cl}
0, & d^{\prime} \notin D_{\mathrm{d}} \\
e^{-\left(\frac{\left|d^{\prime}-d\right|}{t}\right)^{2}}, & d^{\prime} \in D_{\mathrm{d}},
\end{array}\right.
\end{aligned}
$$

where $\left|\Delta_{i j}\right|$ represents the distance between neighboring sites in degrees, $z$ represents the maximum allowable distance between neighboring sites, and $t$ represents the maximum time period over which adjacent dates of observation 
are considered. The temporal weighting is based on observations changing linearly with time, and the spatial weighting is based on traditional Barnes interpolation analysis (Barnes, 1964). When considering the values of these parameters, it is necessary to assess the coherent structure of the measurement variable and assign appropriate spatio-temporal scales.

When all of the plausibility test parameters have been defined, the tests can be implemented in sequence for each observation at each site. In observatory operations, the entire testing procedure is automated in which individual data streams are checked prior to any other data manipulation (as part of the second phase of QC). It is important to note that this approach is only utilized for the definition of plausibility test parameter thresholds. Other internal tests, such as those for consistency and redundancy, should also be performed at a local site where spatio-temporal weighted observations may not be most appropriate.

\section{Results and test examples}

\subsection{Defining parameter thresholds}

\subsubsection{Temperature data}

The implementation of these automated plausibility tests is illustrated using temperature data from a NEON prototype relocatable site in North Sterling, Colorado $\left(40.461903^{\circ} \mathrm{N}\right.$, 103.029266 ${ }^{\circ} \mathrm{W}$; Domain 10 - Central Plains in Fig. 1). These raw temperature observations were recorded in the form of voltage across a platinum resistance thermometer (PRT) (Barber 1950). It should be noted that these data were intentionally not calibrated and contain numerous known errors, which is useful for the purposes of this example.

A time series of 1 month of data sampled at $1 \mathrm{~s}$ intervals in April-May 2011 were chosen as the "historical dataset" for defining the threshold parameters for plausibility testing (Fig. 3). As there are no adjacent observations or historical temperature records for this site, sampling distribution parameters described in Eqs. (4) and (5) simply collapse to Eqs. (2) and (3). The native sampling units of the PRT (millivolts) were used here for the sake of brevity. In practice, much more data will be used for defining threshold test parameters.

From this time series, statistical sampling distributions were constructed by randomly sampling 100 data points, 1000 times. From each sample of 100 data points, a mean, standard deviation were calculated according to Eqs. (2) and (3), respectively. The statistical sampling distribution of these mean values is shown in Fig. 4. Note that with only 1000 samples, the shape of the distribution approaches that of the Gaussian shown in Fig. 2. By applying the central limit theorem to this distribution, the inferred population mean is $113.3 \mathrm{mV}$. In practice, the number of data points available

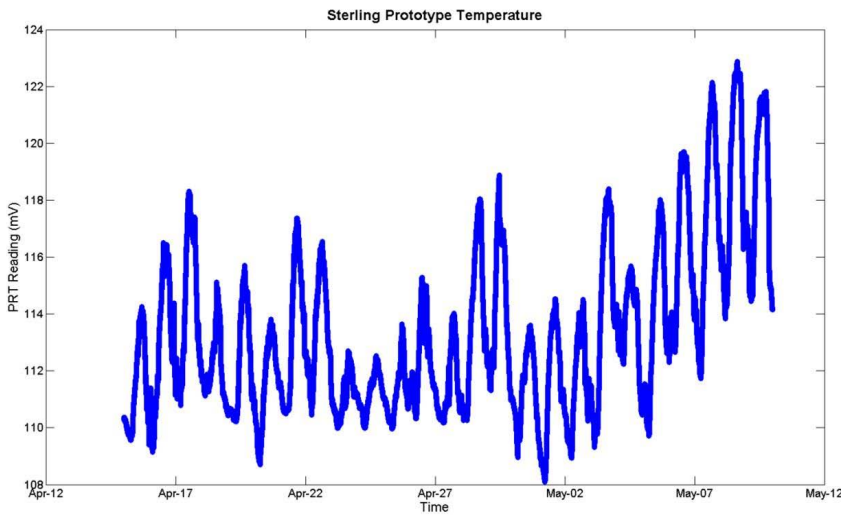

Fig. 3. Time series of platinum resistance thermometer (PRT) observations in April-May 2011 from Domain 10: North Sterling, Colorado. These data were intentionally not calibrated and contain known errors.

will be constrained by the amount of available historical data and temporally/spatially coincident data.

Using the same sampling characteristics, a statistical sampling distribution of the upper and lower range limits $( \pm 2 \sigma$ for each extrema) can be constructed. From this distribution, the value of the upper threshold range can be inferred to be $\mu+2 \sigma=119.2+2 \times(0.74)=120.7$ (see Fig. 5). It should be explicitly noted that daily extrema were not used in constructing these sample distributions as this would not allow the data be independent and randomly sampled, as required in the construction of sampling distributions (although, in practice, a sufficiently large volume of data would remove this restriction). If a sufficiently large enough dataset of daily extrema were available (e.g., years of daily maximum temperature values), then this could be used as an alternative approach for constructing these thresholds. With this threshold parameter now known, the range test simply consists of automatically checking all of the data to ensure that any values above this threshold are flagged according to the above criteria.

In a similar fashion, all parameters for step testing, sigma testing, delta testing, and null testing were calculated by constructing sampling distributions (or, as previously mentioned, they could be defined by the inherent data sampling/acquisition rate of the sensor).

\subsubsection{Precipitation data}

To illustrate the efficacy of this technique on data with an underlying non-Gaussian distribution, the same test parameter threshold definition procedure was carried out on precipitation data.

Hourly accumulated precipitation data collected at the United States Climate Reference Network (USCRN) Station in Boulder Colorado $\left(40.0354^{\circ} \mathrm{N}, 105.5409^{\circ} \mathrm{W}\right)$ spanning 1 January 2009-31 December 2010 was utilized. As these 


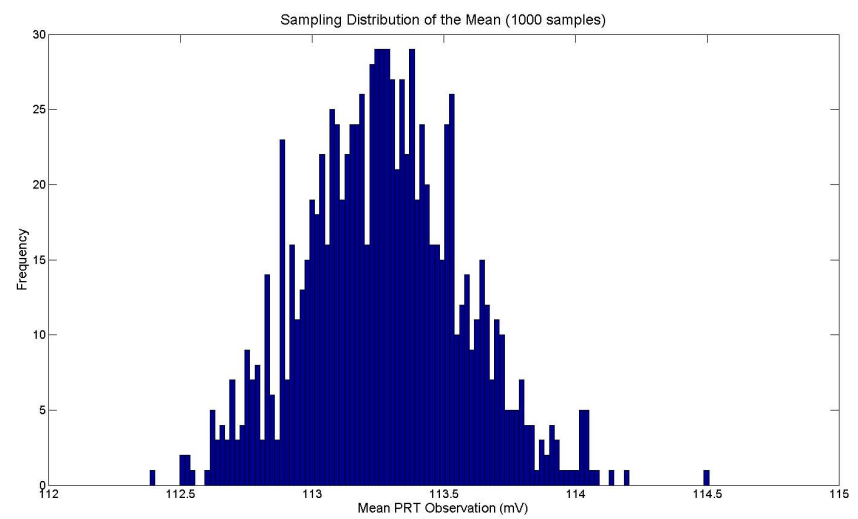

Fig. 4. Statistical sampling distribution of the sample mean PRT observation constructed from 1000 samples.

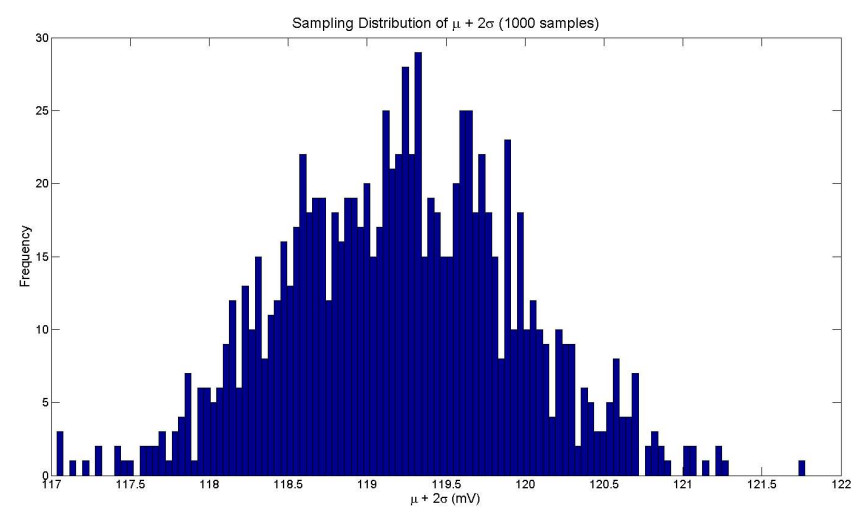

Fig. 5. Statistical sampling distribution of the sample mean maximum PRT observation added to twice the sample standard deviation.

data have already gone through the rigorous QA/QC methods employed by USCRN (https://www.ncdc.noaa.gov/crn/ qcdatasets.html), it is unlikely that any spurious data will be present to skew the test parameter threshold definitions.

A time series of $2 \mathrm{yr}$ of data sampled at $1 \mathrm{~h}$ intervals was chosen to demonstrate the naturally skewed distribution that is expected for midlatitude precipitation (Fig. 6). Due to the high volume of data, statistical sampling distributions were constructed by randomly sampling 10000 data points 10000 times, with replacement. It should be noted that these numbers were chosen rather arbitrarily and, in practice, the size of the available dataset is often the limiting factor in choosing sample sizes. As with the temperature data, from each sample of 10000 data points, a mean and standard deviation were calculated according to Eqs. (2) and (3), respectively. The statistical sampling distribution of the sample maxima is shown in Fig. 7. As is clearly evident, the statistical sampling distribution is closely approximating that of the Gaussian shown in Fig. 2, with an inferred population mean maximum close to $1 \mathrm{~mm} \mathrm{~h}^{-1}$. This value is expected from the large number of nonrain events that occur at this site, which

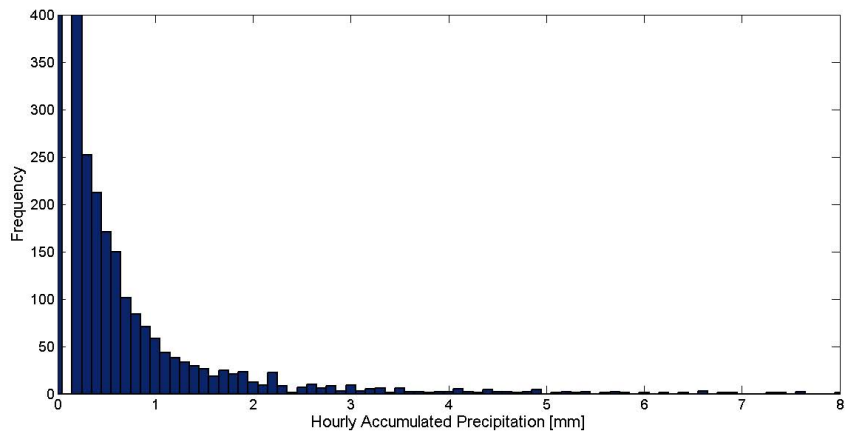

Fig. 6. Distribution of hourly accumulated precipitation at the Boulder, Colorado, USCRN site over 2009-2010. For visual purposes, the domain and range of this figure do not encompass all of the data. The true peak in the distribution actually has a frequency of over 15000 for the zero precipitation event $(0 \mathrm{~mm}$ accumulation), and there are some isolated events where more than $8 \mathrm{~mm}$ of precipitation accumulates in an hour.

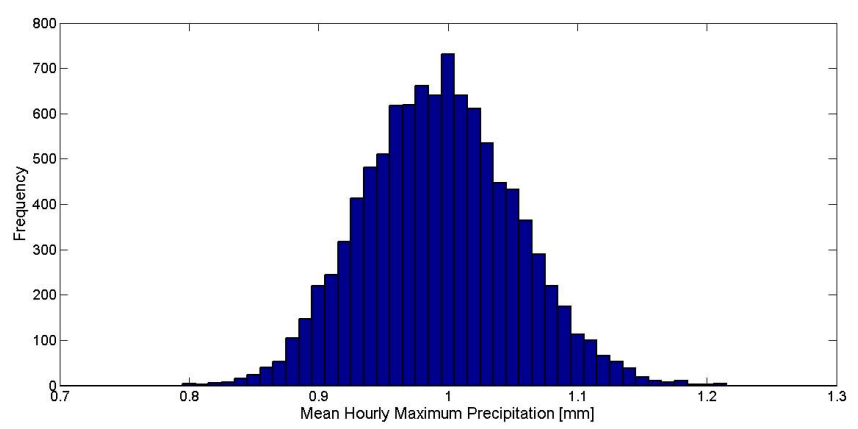

Fig. 7. Statistical sampling distribution of the sample mean maximum hourly precipitation observation added to twice the sample standard deviation.

are assumed to be uniquely represented by the "zero values" (that is, we are assuming that the sensor has always been in working order and that a reading of zero only represents days without precipitation). The resulting range threshold parameters from this sampling distribution are $[0,1.12]$. All values outside of this range should be flagged as potentially implausible. However, because the non-precipitation events (i.e., "zero values") were included in the construction of the sampling distribution, the maximum threshold for rain events is biased toward a lower value than would typically be appropriate for automated plausibility testing. This example demonstrates the necessity of utilizing prior knowledge of the observational dataset to interpret the meaning of the thresholds that are derived.

The time series of these precipitation data, along with the maximum threshold defined by the range test, are shown in Fig. 8. The total dataset consists of 17499 hourly observations with 409 values exceeding the upper range threshold. This is equivalent to approximately $2.3 \%$ of the data being flagged, which is consistent with the expected $2.5 \%$ 


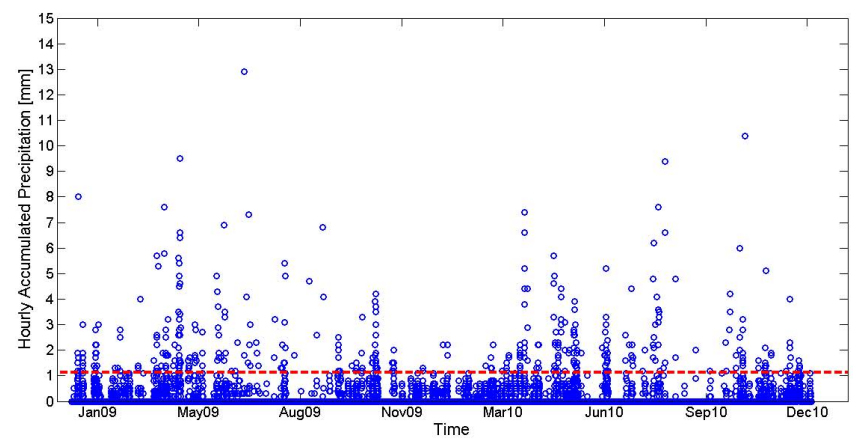

Fig. 8. Time series of hourly accumulated precipitation observations in 2009-2010. The dotted redline is the range parameter threshold beyond which data should be flagged $(\sim 2.3 \%$ of the data should be flagged).

associated with the $\mu+2 \sigma$ threshold defined in the preceding section. In practice, for a quantity such as precipitation, it would be advantageous to relax this definition to a value closer to $\mu+3 \sigma$ as variability associated with extreme events is common. It also should be noted that, in this example of high-quality data, these flagged values are entirely expected to be "revalidated" in the other phases of QA/QC (e.g., in comparisons with redundant sensors) and kept as high-quality data.

\subsubsection{Other data}

In the two previous examples, care was taken to choose the sampling windows and test parameters of interest to ensure that derived Gaussian sampling distribution was representative of meaningful data quality control parameters. In some sense, the selection of these parameters is arbitrary, but there are definitely some parameters that are more optimized than others. When presented with the challenge of defining the parameters for automated plausibility testing on a number of different measurements, several factors should be considered. In particular, the underlying temporal and spatial variability of the quantity of interest must be considered. A broad based assumption is that a measurement is taken at a frequency (and spatial distribution) to capture the natural mean and variance structure of the desired phenomenon.

The primary factor was related to the underlying temporal and spatial variability of the quantity of interest and how well measurement samples capture this variability. For example, ambient air temperature is a slowly changing quantity that typically follows a diurnal cycle. With a measurement sampling rate of $1 \mathrm{~Hz}$, there is confidence that the natural variability of temperature will be well captured by the data. With such a large amount of data, statistical sampling distributions can be created that will adequately characterize the test parameter of interest (e.g., daily maximum temperature). Furthermore, when this is the case, "data windows" can be defined in which subsets of data can be further scrutinized for plausible variability.

For the converse case, where a quantity of interest is a rapidly changing variable and it is not sampled very frequently, it is unlikely that the dataset will be representative of the true natural variability. For example, wind speed and direction is a quantity that changes rapidly, sometimes with diurnal dependence. If the wind were only measured once every hour, these observations would not be able to capture the actual variability of the wind, and any sigma or delta test parameters would not be applicable for plausibility testing, i.e., violating the assumption noted above. In such cases, it is recommended that plausibility test thresholds be set conservatively so that data quality is heavily scrutinized a priori until such time that an adequate dataset can be compiled.

Irregularly occurring variables also pose some challenges. For example, precipitation measurements may have the capability to observe with very high frequency, but as precipitation does not typically follow a recurring cycle, its high degree of natural variability makes threshold definition very difficult. Most plausibility tests related to variability will often not be applicable, nor will a minimum range value be useful (i.e., there are many days where no precipitation occurs). However, as illustrated in the example above, maximum plausible hourly accumulated precipitation can be defined and utilized for automated quality control. This further demonstrates that the utility of a particular plausibility test is unique for each measurement.

Of course, if a novel measurement is being conducted for the first time and there is inadequate knowledge of the underlying sampling distribution and its ability to capture natural phenomena, it will be challenging to determine any of these parameters. In such a case, it is recommended that plausibility tests not be used at all until an adequate sample of these data is obtained for inspection first.

\subsection{Application to test data}

The same prototype temperature observations from Sect. 3.1.1 were used to illustrate the efficacy of plausibility testing by employing these calculated threshold parameters. A time series of 2 months of data sampled at $1 \mathrm{~s}$ intervals is shown in Fig. 6. This represents approximately $5.2 \times 10^{6}$ data points. These data will be considered the "test" data upon which all of the plausibility tests should be conducted, and, via visual inspection, it is obvious that there are some poor quality data values (such as those that read " $0 \mathrm{mV}$ "). Using the derived test parameters, these data were processed with all six of the automated plausibility tests. The data that failed these tests were flagged (Fig. 7).

The automated plausibility tests resulted in the following analyses (e.g., data quality report with additional annotations for explanation): 


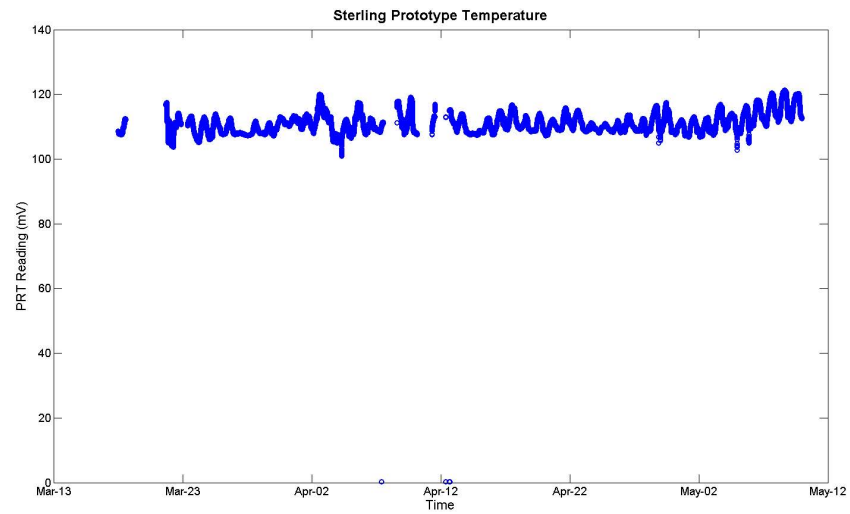

Fig. 9. Time series of platinum resistance thermometer (PRT) observations in March-May 2011 from Domain 10: North Sterling, Colorado. These data were intentionally not calibrated and contain known errors.

- Range test: the range thresholds were found to be 104.04 to $118.56 \mathrm{mV}$. There were 150643 values outside of this range, resulting in $3.2 \%$ being flagged.

- Step test: the step threshold was found to be $0.2015 \mathrm{mV}$. There were 36 values greater than this step resulting in 7.5 parts per million ( $\mathrm{ppm}$ ) being flagged, relative to the size of the total dataset.

- Sigma test: the sigma thresholds were found to be 2.57 to $3.56 \mathrm{mV}$. Because the observations in this dataset have considerable bias and variation (as intended), the lower sigma threshold was much larger than the anticipated noise in the baseline observations. For this reason, the lower variance test was not applied and the plausibility of the variation over small timescales was assessed solely by the step tests and delta tests. While this is not nominally optimal, it does demonstrate appropriate use for datasets with large random variability (i.e., noise), such as this. Utilizing the test for only the upper sigma range and applied over a sliding window of 500 data points, there were 999 instances where the variance was greater than the acceptable sigma range, resulting in $0.02 \%$ of the data being flagged.

- Delta test: due to the narrow range of variation in the observations, the delta threshold was found to be negative and, consequently, set to 0 for this test. This will happen with observational datasets of this nature and should typically have a threshold set at the precise resolution of the sensor. For this particular prototype dataset, this value was not available and the delta test was not applied. Nominally, the delta threshold would be applied over a rolling domain sequence of $\sim 100$ data points, or similar.

- Null test: the null threshold was found to be 12.6 missing data points. This was applied over a moving window

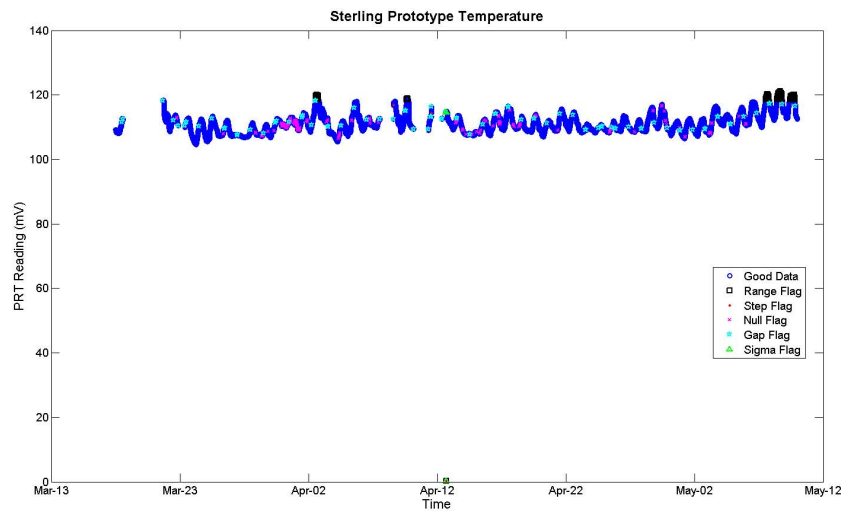

Fig. 10. Time series of platinum resistance thermometer (PRT) observations in March-May 2011 from Domain 10: North Sterling, Colorado, but data that have failed QC tests are flagged as suspect. The different colored symbols represent the different flags that have been applied by the automated plausibility testing.

sequence of 50 data points resulting in 42804 instances where there were more missing values than the threshold, causing $0.9 \%$ to be flagged.

- Gap test: the gap threshold was chosen to be 5 min (this was an arbitrary choice and not based on any statistical calculations). There were 116 time gaps greater than this threshold, resulting in $24 \mathrm{ppm}$ being flagged.

By combining all of the plausibility tests together, this resulted in 194581 data points being flagged, or $4.1 \%$ of all the data in question. It should be noted that many poor observations were flagged by multiple tests, so the total number of flagged data points was not simply the linear addition of flagged data points from individual failed tests.

It should also be noted that these tests can be made more efficient through strategic sequencing. For example, data points that are flagged by the range test could potentially be disregarded when utilizing the sigma test. This would ensure that the sigma test is more representative of the true variance structure of the dataset in question and it will decrease the likelihood of data points getting flagged twice. Of course, there are circumstances where the nature of the observations does not lend itself to this sort of sequencing, so, as with all plausibility tests, the underlying structure of the data must be considered when making these decisions. The implementation of such efficiencies at NEON is done through the use of a quality metric scheme that aggregates data quality flags to inform more sophisticated decision making. The details of this scheme will be discussed in a subsequent publication.

The same time series of observations, with all flagged data points removed, is shown in Fig. 8. In practice, of course, flagged data points would undergo additional phasetwo quality control before ever being permanently removed from the published data record. General statistics of the data flags are also maintained for regular scrutiny and auditing in 


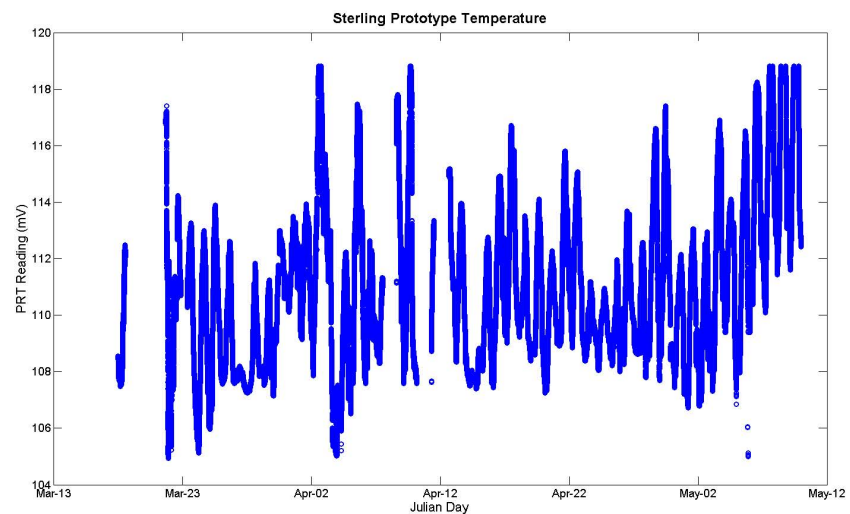

Fig. 11. Time series of platinum resistance thermometer (PRT) observations in March-May 2011 from Domain 10: North Sterling, Colorado, but all of the flagged data have been removed, leaving only observations that passed all automated plausibility tests $(\sim 4.1 \%$ of the raw data was flagged).

phase-three QC. Consistent with NEON's data-sharing policy, records of the flagged data and complete quality control reports will be made freely available to all interested stakeholders. It is hoped that this policy of transparency and availability will become the standard across all observatories and networks.

\section{Discussion}

\subsection{Comparisons with other data quality control techniques}

By using a data-driven approach to automated quality control, human interaction is minimized and arbitrary decisions can be avoided. This objective approach avoids ambiguity that has traditionally been associated with quality control among different sensors and provides an extensive framework upon which observatories with long observational lifetimes can be sustained (e.g., NEON's 30 yr planned lifespan). As part of an overall QA plan, this approach must be used in conjunction with other quality control and assurance procedures (phases 2-3).

In contrast to other QC approaches (such as those outlined in Table 1), this data-driven approach avoids the use of numerous assumptions. Many networks employ a subset of the plausibility tests discussed here in a way that utilizes static threshold parameters and/or relies heavily on human-based intervention. Utilizing these automated plausibility tests not only minimizes human action, it also allows for thresholds that are updated dynamically as more data are collected. In this sense, this QC approach "learns" from actual data and ultimately generates an optimized algorithm without any explicit modeling of variable behavior. This avoids the need for assuming an underlying statistical distribution and eliminates all prognostic modeling. This is advantageous for many vari- ables that have not been previously observed in a large-scale context and, therefore, are not well understood. Modeling the behavior of NEON's 14000 simultaneous observations is also computationally demanding, and potentially requires a significant level of verification and validation before it can be implemented in any automated way.

However, this approach is not without its limitations. In particular, the lifetime of an environmental observatory (e.g., NEON) and its focus on climate change could result in a record of observations where dynamic changes have significantly modified threshold parameters. For example, in a warming climate, temperature values that may seem exceptionally high or variable in 2012 may in fact be well within normal conditions in 2042. As new data are collected and the threshold parameters are updated, it is inevitable that published data will need to be reprocessed into newer versions. Climatological averages are typically recalculated every 10 years, so it can be expected that these changes will occur at least this frequently.

The converse limitation is also true. As with most statistical approaches, there is inevitably an element of arbitrary choice when it comes to setting threshold limits. In the examples shown here, a two-standard deviation offset was chosen for illustrative purposes. It should be noted that this resulted in a significant number of "false-positive" plausibility test results in which seemingly good data were flagged (see Fig. 7). This problem is typically managed in a number of ways: (A) by choosing very liberal thresholds, (B) by implementing a second phase of quality assurance in which flagged values are further scrutinized, or (C) both. These options have their advantages and disadvantages. In choosing option (A), "good data" will very likely pass the tests and only the most egregious of implausible data points will be flagged. However, this approach does run the risk of allowing more "bad data" to be accepted as false negatives. In choosing option (B), more conservative thresholds can be chosen to ensure that as many of the implausible data points as possible are flagged. The downside to this approach is that all of the flagged values need to be revisited in a second phase of data verification to sort the "good from the bad", which consumes further resources. In the implementation of NEON's QC approaches, option (B) has been chosen.

A fundamental limitation that should also be mentioned is that of utilizing the central limit theorem as the foundation of defining all plausibility testing thresholds. The central limit theorem works well for distributions that are nearly Gaussian. For statistics that have an underlying bimodal or more complex distribution, the theorem will force the data to conform to a Gaussian shape. For most of the measurement thresholds considered by automated sensors, this will indeed be the case, but for some measurements that do not yet have an extensive historical archive or if a measurement is still novel, it remains to be seen if this approach is valid. In some sense, a lot of samples need to be made before evaluating a QC approach. 


\subsection{Toward better approaches}

While automated data quality control through plausibility testing establishes the core of an efficient and sophisticated observatory quality assurance plan, it still requires long-term maintenance. To this end, it must be designed with sufficient flexibility to adapt to unforeseen quality control challenges that will undoubtedly arise in the future. To assist with enhancing QC flexibility, we recommend complete records of data flags and quality control reports be maintained throughout the lifetime of the observatory. This permits the recalculation of running statistics of how threshold parameters for particular measurements (and locations) behave over time, and will inform how to manage this challenge.

This record of data quality will be augmented by a thorough auditing plan that will not only scrutinize generated data but also the quality control of this data. Independent, random auditing is another method through which data QC can be tested for efficacy. This will consist of audits on real sensor measurements as well on test datasets that have expected outcomes. Failure to meet audit goals will result in immediate scrutiny of the QC tests and be followed by significant testing and potentially reimplementation of the QC threshold parameters (and associated data reprocessing). All of these details will be included as part of the data quality record and should be part of the data providence and communicated to the data-user community. While extensive data quality auditing requires additional resources, it is necessary to establish the "quality of quality control."

One way to maintain flexibility within the quality control system is to ensure that all raw data are always archived. As data quality control evolves, having the raw data available ensures that reprocessing to enhance data quality can always be achieved. As part of NEON's QA plan, the intention of QC is to identify (and remedy) problems, not simply eliminate data outliers. As such, no data should ever be deleted and the raw data should be permanently maintained by the host Observatory and freely available to interested data users.

\subsection{Future applications}

Automated, data-driven QC could easily be implemented at numerous other automated sensing networks. The most obvious candidate for this is meteorological observatories/networks. Often the historical construction of the infrastructure utilized by most met services limits the capacity for such data-intensive QC. However, after an initial investment of resources to implement this system, the maintenance required for this automated QC is minimal, and the resulting data quality enhancement would more than offset these costs. The question of how these automated QC tests would be applied to historical data raises another set of issues that would need to be addressed on a case-by-case basis.

In addition to met services, there are many existing networks (such as those in Table 1) that could benefit from more automated QC techniques. Regardless of the measurement, instrumentation, and the cyberinfrastructure, these plausibility tests can almost always be implemented and used to enhance data quality. It is always necessary that this be implemented as part of an overarching QA plan and, depending on the observations of interest, may require very thorough data auditing. For instances where a series of data is processed using complex time series analysis (e.g., Fourier transforms, wavelet analysis, etc.), care must be taken to ensure that automated corrections applied in one space do not yield spurious results in another space. For instance, the removal of outliers from one time series could cause "jump discontinuities" that contribute to large oscillations or "ringing" in the Fourier transform of this time series. In these cases, data quality auditing can be used to identify where risks of such results are probable, and the automated QC can be adjusted accordingly. For the vast majority of observations, these standard plausibility tests will be sufficient for enhancing data quality.

One of the biggest challenges for moving toward global datasets of observations is that of network interoperability. Without standardized approaches to network observations, no two sets of data can adequately be combined in any way. The future of network interoperability can only be enhanced when a well-planned, uniform approach to data QC is adopted. While it is obvious that different observing networks will have differing demands for QC approaches and implementation, "phase 1" plausibility tests will almost uniformly be required in one capacity or another. Using these automated QC approaches can only assist with enhancing data quality and, consequently, data usage.

\section{Conclusions}

With the rapid growth of national and international sensor networks, the demand for data quality control in ecology will grow to an unprecedented level. Network interoperability can be best achieved by having unified approaches to QA/QC methods and, it is hoped, that the methods presented here will act as a primer for all other networks. By adopting methods that can be implemented rapidly, such as these, a consistent framework for data management can be established. It is only through the use of these standardized approaches that globalscale ecological questions can ever be addressed.

Acknowledgements. The authors wish to thank S. Berukoff for providing the temperature data used for algorithm prototyping. E. Ayres, H. Luo, R. Tawa, and F. Pradeau provided informative discussions throughout the preparation of the manuscript. Thoughtful insight was provided by R. Clement, Z. Nesic, S. Del Greco, C. Fiebrich, K. Hubbard, H. McCaughey, M. Menne, D. Papale, and C. Staudhammer. The National Ecological Observatory Network is a project sponsored by the National Science Foundation and managed under cooperative agreement by NEON, Inc. This material is based upon work supported by the National Science 
Foundation under the following grants: EF-1029808, EF-1138160, EF-1150319, and DBI-0752017. Any opinions, findings, and conclusions or recommendations expressed in this material are those of the authors and do not necessarily reflect the views of the National Science Foundation.

Edited by: P. Stoy

\section{References}

Baldocchi, D., Falge, E., and Gu, L.: FLUXNET: A new tool to study the temporal and spatial variability of ecosystem-scale carbon dioxide, water vapor, and energy flux densities, B. Am. Meteorol. Soc., 82, 2415-2434, 2001.

Barber, C. R.: Platinum resistance thermometers of small dimensions, J. Sci. Instrum., 27, 47-49, 1950.

Barnes, S. L.: A Technique for Maximizing Details in Numerical Weather Map Analysis, J. Appl. Meteorol., 3, 396-409, 1964.

Brantley, S. L., White, T. S., White, A. F., Sparks, D., Richter, D., Pregitzer, K., Derry, L., Chorover, J., Chadwick, O., April, R., Anderson, S., and Amundson, R. : Frontiers in exploration of the critical zone: Report of a workshop sponsored by the National Science Foundation (NSF), 24-26 October 2005, Newark, USA, 2006.

DeFries R., Houghton, R. A., Hansen, M. C., Field, C. B., Skole, D., and Townshend, J.: Carbon emissions from tropical deforestation and regrowth based on satellite observations for the 1980s and 1990s, P. Natl. Acad. Sci. USA, 99, 14256-14261, 2002.

Durre, I., Menne, M. J., and Vose, R. S.: Strategies for Evaluating Quality Assurance Procedures, J. Appl. Meteorol. Clim., 47, 1785-1791, 2008.

Essenwanger, O. M.: Analytical procedures for the quality control of meteorological data., Meteorological Observations and Instrumentation: Meteorological Monograph, Am. Meteorol. Soc., 33, 141-147, 1969.

Fiebrich, C. A., Grimsley, D. L., McPherson, R. A., Kelser, K. A., and Essenberg, G. R.: The value of routine site visits in managing and maintaining quality data from the Oklahoma Mesonet, J. Atmos. Ocean. Tech., 23, 406-416, 2006.

Fiebrich, C. A., Morgan, C. R., McCombs, A. G., Hall Jr., P. K., McPherson, R. A.: Quality assurance procedures for mesoscale meteorological data, J. Atmos. Ocean. Tech., 27, 1565-1582, 2010.

Foken, T. and Wichura, B.: Tools for quality assessment of surfacebased flux measurements, Agric. For. Meteorol., 78, 83-105, 1996.

Foken, T., Gockede, M., Mauder, M., Mahrt, L., Amiro, B., and Munger, J. W.: Post-field data quality control, in: Handbook of Micrometeorology, edited by: Lee, X., Massman, W., Law B., Kluwer Academic Publishers, Boston, USA, 181-203, 2004.

Franklin, J. F., Bledsoe, C. S., and Callahan, J. T.: Contributions of the Long-Term Ecological Research Program, Bioscience, 40, 509-523, 1990.

Gandin, L. S.: On automatic quality control of current meteorological information (in Russian), Meteorologiya i Gidrologiya, 3, 3-13, 1969.

Gandin, L. S.: Complex quality control of meteorological observations, Mon. Weather Rev., 116, 1137-1156, 1988.
Graybeal, D. Y., DeGaetano, A. T., and Eggleston, K. L.: Improved Quality Assurance for Historical Hourly Temperature and $\mathrm{Hu}-$ midity: Development and Application to Environmental Analysis, J. Appl. Meteorol., 43, 1722-1735, 2004.

Group on Earth Observations (GEO): Report on Progress: Beijing Ministerial Summit, GEO Secretariat, Geneva, Switzerland, 2010.

Hanson, P. C.: New ecological insights through the Global Lake Ecological Observatory Network (GLEON), Ecol. Sci., 27, 300302, 2008.

Hasu, V. and Aaltonen, A.: Automatic minimum and maximum alarm thresholds for quality control, J. Atmos. Ocean. Tech., 28, 74-84, 2011.

Institute of Medicine (IOM): Environmental decisions in the face of uncertainty, The National Academies Press, Washington, DC, 209 pp., 2013.

ISO/IEC 17025: General requirements for the competence of testing and calibration laboratories, Second Edition, International Standards Office, Geneva, Switzerland, 2005.

Karl, T. R., Derr, V. E., Easterling, D. R., Folland, C. K., Hofmann, D. J., Levitus, S.,Nicholls, N., Parker, D. E., and Withee, G. W.: Critical issues for long-term climate monitoring, Clim. Change, 31, 185-221, 1995.

Keller, M., Schimel, D., Hargrove, W., and Hoffman, F.: A continental strategy for the National Ecological Observatory Network, Front. Ecol. Environ., 6, 282-284, 2008.

Loescher, H. W., Ocheltree, T., Tanner, B., Swiatek, E., Dano, B., Wong, J., Zimmerman, G., Campbell, J. L., Stock, C., Jacobsen, L., Shiga, Y., Kollas, J., Liburdy, J., and Law, B. E.: Comparison of temperature and wind statistics in contrasting environments among different sonic anemometer-thermometers, Agr. Forest Meteorol., 133, 119-139, 2005.

Margolis, H. A., Flanagan, L. B., and Amiro, B. D.: The FluxnetCanada Research Network: Influence of climate and disturbance on carbon cycling in forests and peatlands, Agr. Forest Meteorol., 140, 1-5, 2006.

McPherson, R. A., Fiebrich, C. A., Crawford, K. C., Elliott, R. L., Kilby, J. R., Grimsley, D. L., Martinez, J. E., Basara, J. B., Illston, B. G., Morris, D. A., Kloesel, K. A., Stadler, S. J., Melvin, A. D., Sutherland, A. J., and Shrivastava, H.: Statewide monitoring of the mesoscale environment: A technical update on the Oklahoma Mesonet, J. Atmos. Ocean. Tech., 24, 301-321, 2007.

Meek, D. W. and Hatfield, J. L.: Data quality checking for single station meteorological databases, Agr. Forest Meteorol, 69, 85109, 1994.

Munger, J. W., Loescher, H. W., and Luo, H.: Measurement, tower, and site design considerations, in: The Eddy Covariance Handbook, edited by: Aubinet, M., Vesala, T., and Papale, D., Springer Verlag, 22-53, 2012.

National Research Council (NRC): A review of the U.S. Global Change Research Program's Draft Strategic Plan. National Academies Press, Washington DC, 62 pp., 2011.

O'Brien, K. J. and Keefer, T. N.: Real-time data verification: Computer Applications in Water Resources, in: Proceedings of the Specialty Conference Sponsored by the Water Resources Planning and Management Divison and the Buffalo Section of the American Society of Civil Engineers, edited by: Torno, H. C., Buffalo, New York, American Society of Civil Engineers, New York, New York, USA, 764-770, 1985. 
Ocheltree, T. O. and Loescher, H. W.: Design of the AmeriFlux portable eddy-covariance system and uncertainty analysis of carbon measurements, J. Atmos. Ocean. Tech., 24, 1389-1409, 2007.

Peppler, R. A., Long C. N., Sisterson D. D., Turner, D. L., Bahrmann, C. P., Christensen, S. W., Doty, K. J., Eagan, R. C., Halter, T., Ivey, M. D., Keck, N. N., Kehoe, K. E., Liljegren, J. C., Macduff, M. C., Mather, J. H., McCord, R. A., Monroe, J. W., Moore, S. T., Nitschke, K. L., Orr, B. W., Perez, R. C., Perkins, B. D., Richardson, S. J., Sonntag, K. L., Voyles, J. W., and Wagener, R.: An Overview of ARM Program Climate Research Facility Data Quality Assurance, Open Atmos. Sci. J., 2, 192-216, 2008.

Porter, J. H., Nagy, E., Kratz, T. K., Hanson, P., Collins, S. L., and Arzberger, P.: New Eyes on the World: Advanced Sensors for Ecology, Bioscience, 59, 385-397, 2009.

Rice, J. A.: Mathematical Statistics and Data Analysis, Third Edition, Duxbury Press, Belmont, California, USA, 2007.

Schaefer, G. L., Cosh, M. H., Jackson, T. J.: The USDA Natural Resources Conservation Service Soil Climate Analysis Network (SCAN), J. Atmos. Ocean. Tech., 24, 2073-2077, 2007.

Schimel, D., Keller, M., Berukoff, S., Kao, R., Loescher, H. W., Powell, H., Kampe, T., Moore, D., and Gram, W.: NEON Science Strategy: enabling continental-scale ecological forecasting, National Ecological Observatory Network, Boulder, Colorado, www.neoninc.org/science/sciencestrategy, 2011.

Schneider, D. C.: The rise of the concept of scale in ecology, Bioscience, 51, 545-553, 2001.

Shafer, M. A., Fiebrich, C. A., Arndt, D. S., Fredrickson, S. E., and Hughes, T. W.: Quality Assurance Procedures in the Oklahoma Mesonetwork, J. Atmos. Ocean. Tech., 17, 474-494, 2000.
Smith, S. R., Camp, J. P., Legler, D. M.: TOGA/COARE handbook of quality control procedures and methods for surface meteorology data, Tech. Rep. 96-3, Center for Ocean Atmospheric Prediction Studies, Florida State University, Tallahassee, FL, 1996.

Stokes, G. M. and Schwartz, S. E.: The Atmospheric Radiation Measurement (ARM) Program: Programmatic background and design of the Cloud and Radiation Test Bed, B. Am. Meteorol. Soc., 75, 1201-1221, 1994.

Suresh, S.: Research funding: Global challenges need global solutions, Nature, 490, 337-338, doi:10.1038/490337a, 2012.

Taylor, J. R. and Loescher, H. W.: NEON's Fundamental Instrument Unit Dataflow and Quality Assurance Plan, NEON.011009, National Ecological Observatory Network, Boulder, Colorado, 2012.

United States Global Change Research Program (USGCRP): Climate Assessment report; Third Assessment, 2013.

Wagner, R. J., Boulger Jr., R. W., Oblinger, C. J., and Smith, B. A.: Guidelines and Standard Procedures for Continuous WaterQuality Monitors: Station Operation, Record Computation, and Data Reporting, Tech. Rep. 1-D3, US Geological Survey, Reston, VA, 2006.

Zacharias, S., Bogena, H. R., Samaniego, L., Mauder, M., Fuß, R., Pütz, T., Frenzel, M., Schwank, M., Baessler, C., ButterbachBahl, K., Bens, O., Borg, E., Brauer, A., Dietrich, P., Hajnsek, I., Helle, G., Kiese, R., Kunstmann, H., Klotz, S., Munch, J. C., Papen, H., Priesack, E., Schmid, H. P., Steinbrecher, R., Rosenbaum, U., Teutsch, G., and Vereecken, H.: A Network of Terrestrial Environmental Observatories in Germany, Vadose Zone J., 10, 955-973, 2011. 